\title{
SOLVING A SYSTEM OF NONLINEAR INTEGRAL EQUATIONS AND EXISTENCE OF ASYMPTOTICALLY STABLE SOLUTIONS
}

\author{
Le Thi Phuong Ngoc And Nguyen Thanh Long
}

Abstract. The paper is devoted to the study of a system of nonlinear integral equations. First, this system is reduced to a fixed point problem of a nonlinear integral operator and hence we can give suitable assumptions and using a fixed point theorem of Krasnosel'skii type in order to obtain the existence of solutions. Next, we prove the existence of asymptotically stable solutions for the above system. In order to illustrate the results, an example is also presented.

Mathematics subject classification (2010): 45G10, 47H10, 47N20, 65J15.

Keywords and phrases: the fixed point theorem of Krasnosel'skii type, a system of nonlinear integral equations, contraction mapping, completely continuous, asymptotically stable solution.

\section{REFERENCES}

[1] C. Avramescu, Some remarks on a fixed point theorem of Krasnosel'skii, Electron. J. Qual. Theory Differ. Equ., 5 (2003), 1-15.

[2] C. Avramescu, C. Vladimirescu, Asymptotic stability results for certain integral equations, Electron. J. Differ. Equ., 126 (2005), 1-10.

[3] C. Avramescu, C. Vladimirescu, An existence result of asymptotically stable solutions for an integral equation of mixed type, E. J. Qualitative Theory of Diff. Equ., 25 (2005), 1-6.

[4] C. Avramescu, C. Vladimirescu, On the existence of asymptotically stable solutions of certain integral equations, Nonlinear Analysis, 66, 2 (2007), 472-483.

[5] C. Avramescu, C. Vladimirescu, Fixed point theorems of Krasnoselskii' type in a space of continuous functions, Fixed Point Theory, 5, 2 (2004), 181-195.

[6] C. Corduneanu, Integral equations and applications, Cambridge University Press, New York, 1991.

[7] B. C. Dhage, S. K. NTouyas, Existence results for nonlinear functional integral equations via a fixed point theorem of Krasnoselskii-Schaefer type, Nonlinear Studies, 9 (2002), 307-317.

[8] B. C. DHAGE, Existence results for nonlinear functional integral equations via nonlinear alternative of Leray-Schauder type, Annales Scientifiques de l'Universite de Jassy (Analele Ştiintifice ale Universităţii "Al.I.Cuza" din Iaşi), Vol. LII, (1) (2006), 113-126.

[9] B. C. DHAGE, Attractivity and positivity results for nonlinear functional integral equations via measure of noncompactness, Differ. Equ. Appl., 2 , 3 (2010), 299-318.

[10] G. GABOR, On the acyclicity of fixed point sets of multivalued maps, Topol. Methods Nonlinear Anal., 14, 2 (1999), 327-343.

[11] L. H. HoA, K. Schmitt, Periodic solutions of functional differential equations of retarded and neutral types in Banach spaces, Boundary Value Problems for Functional Differential Equations, Editor Johnny Henderson, World Scientific, 1995, 177-185.

[12] S. LAng, Analysis II, Addison-Wesley, Reading, Mass., California London, 1969.

[13] L. T. P. NGOC, N. T. Long, On a fixed point theorem of Krasnosel'skii type and application to integral equations, Fixed Point Theory and Applications, Vol. 2006 (2006), Article ID 30847, 24 pages.

[14] L. T. P. NGOC, N. T. Long, The Hukuhara-Kneser property for a nonlinear integral equation, Nonlinear Analysis, Theory, Methods \& Applications, Series A: Theory and Methods, 69, 11 (2008), 3952-3963. 
[15] L. T. P. NGoc, N. T. Long, Applying a fixed point theorem of Krasnosel'skii type to the existence of asymptotically stable solutions for a Volterra-Hammerstein integral equation, Nonlinear Analysis, Theory, Methods \& Applications, Series A: Theory and Methods, 74, 11 (2011), 3769-3774.

[16] I. K. PURNARAS, A note on the existence of solutions to some nonlinear functional integral equations, E. J. Qualitative Theory of Diff. Equ., 17 (2006), 1-24.

[17] C. Vladimirescu, Remark on Krasnoselskii's fixed point theorem, Nonlinear Analysis: Theory, Methods \& Applications, 71, 3-4 (2009), 876-880.

[18] K. Yosida, Functional Analysis, Springer-Verlag, New York Berlin, Göttingen Heidelberg, Vol. 123, 1965. 